\title{
Primera CAMPAÑa DE EXCAVACIÓN EN El POBlado IBÉRICO DEL Pico DE loS Ajos (Yátova, València)
}

DAVID QUIXAL SANTOS ${ }^{1}$, CONSUELO MATA PARREÑO ${ }^{\circledR}$, CLARA MARTÍNEZ MORENO $^{1}$

(1) Dpt. de Prehistòria, Arqueologia i Història Antiga. Universitat de València.david.quixal@uv.es, clamarmo@alumni.uv.es

(2) GRAM, Departament de Prehistòria, Arqueologia i Història Antiga. Universitat de València. consuelo.mata@uv.es

El Pico de los Ajos es un poblado fortificado ubicado en la cima de Sierra Martés, cadena montañosa que separa los actuales términos municipales de Yátova y Cortes de Pallás (València). Pese a tratarse de uno de los yacimientos ibéricos más destacados de la provincia, declarado BIC y conocido por el hallazgo de una importante colección de plomos escritos en íbero (Fletcher 1980), no se había realizado ningún tipo de intervención arqueológica hasta el momento. No obstante, el poblado cuenta con estudios de su sistema defensivo oriental (Díes y Gimeno 1995), así como aproximaciones a su extensión, cronología y funcionalidad (Quixal 2010; 2013).

Su principal amenaza es la grave actividad expoliadora que ha sufrido, y por desgracia aún sufre, desde las décadas finales del siglo pasado, sobre todo a raíz del hallazgo de los plomos. Ello ha provocado que buena parte de las plataformas y laderas que constituyen el yacimiento estén plagadas de agujeros de clandestino, tanto antiguos como modernos. Buena parte de los materiales de este yacimiento, depositados en el Museu de Prehistòria de València y el Museo Arqueológico de Buñol, proceden de excavaciones no regladas. Esta circunstancia, sumada al interés de recuperar y difundir el patrimonio histórico local, motivó al Ayuntamiento de Yátova a iniciar un proyecto de colaboración con la Universitat de València, fruto del cual ha sido posible el inicio de los trabajos arqueológicos.

La primera campaña se desarrolló del 17 al 31 de julio del 2017 por parte de un equipo compuesto por los codirectores de la excavación, Consuelo Mata y David Quixal, juntamente con la Dra. Vanessa Albelda, así como los estudiantes del grado de Historia Clara Martínez, Joaquim Botella, Jaume Alberola, Raquel Anchel, José Luis Azorín, Isabel García, Diana Navarro, Darío Pérez, Ana Serrano y Adrián Sotos. Al tratarse de una campaña inicial y reducida, los objetivos se limitaron a establecer secuencias de ocupación y trazar directrices de cara futuras campañas.

El poblado tiene unas 2,5 ha de superficie. Su perímetro está adaptado a la propia forma de la cima, teniendo una anchura muy reducida, pero con casi $500 \mathrm{~m}$ de longitud desde el Sector 1 o plataforma más occidental de la sierra, hasta el sistema defensivo que cierra el poblado por el E, poco antes de llegar al punto geodésico del Pico Martés. En toda la longitud encontramos una serie de espacios diferenciados con abundante material superficial. 


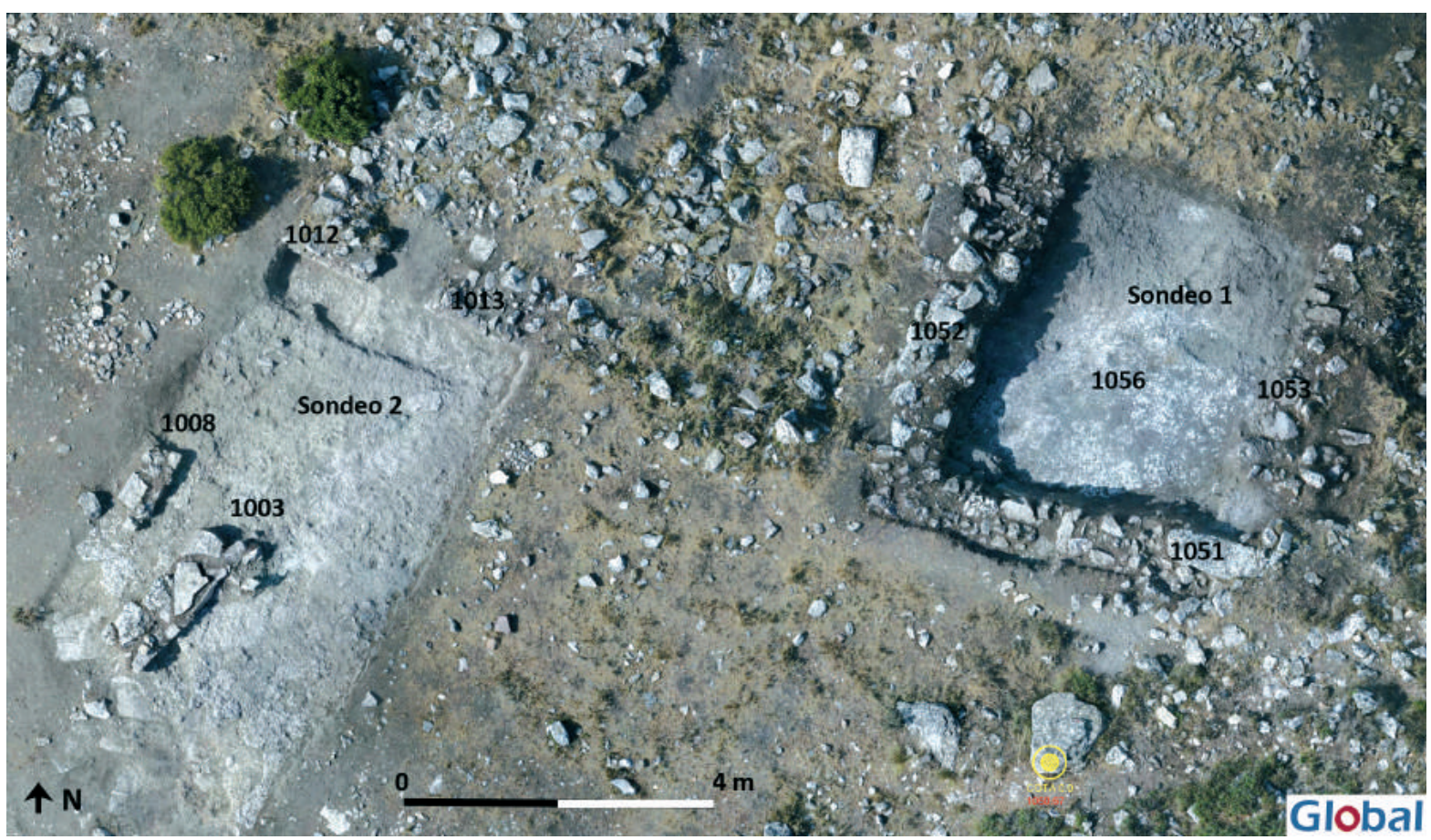

Fig. 1: Ortofoto del área excavada en el sector 1 durante la campaña de 2017.

A diferencia de otros poblados ibéricos en alto, la sierra escogida como ubicación no presenta una fisonomía de cima amesetada, sino que alterna continuamente zonas planas con otras en pendiente.

Los trabajos se centraron en el Sector 1, uno de los más afectados por la actividad clandestina, dado que incluso antes de comenzar ya se podían seguir alineaciones de piedras en superficie (fig. 1). En especial, destaca la presencia de un largo muro longitudinal, de unos $30 \mathrm{~m}$ de longitud, que atraviesa la plataforma más o menos por el centro. Al $\mathrm{N}$ de dicho muro, se observa una serie de muros perpendiculares al mismo, con una separación aproximada entre ellos de 4 / 4,30 m, definiendo y modulando hasta seis o siete departamentos en batería.

En dicho sector la excavación se dividió en dos sondeos muy próximos entre sí. El Sondeo 1 corresponde a uno de los departamentos de la citada batería, supuestamente el más oriental. Lo hemos denominado Departamento 1, a falta de determinar si existiría otro más al E. Por otra parte, el Sondeo 2 se dispuso en el centro de la plataforma. Esta división en sondeos es completamente artificial y únicamente buscaba organizar mejor los trabajos en esta área, ya que el objetivo final es excavar en extensión.
La elección de dicho Departamento 1 se justifica por el buen estado de conservación de uno de sus muros, visible en superficie, y porque el paquete de tierra de su interior no parecía muy alterado, a pesar de contar con un pequeño agujero de clandestino muy reciente. Los trabajos arqueológicos han permitido definir tres lados con estructuras murarias: O (1052), S (1051) y E (1053). En el último de éstos, el lado oriental, el muro se completa en su tramo inicial con un recorte en la roca, que se talló para servir de basamento. En el ángulo SO del departamento hemos documentado una escalera compuesta por varios peldaños, de ahí que el acceso desde el $\mathrm{S}$ (calle o espacio abierto) se realizaría por ese lado y el departamento sería un semisótano. El cierre del departamento por el $\mathrm{N}$ ha quedado pendiente para una futura campaña. El departamento cuenta con 3,40 m de anchura interior y se ha excavado 4,30 m de longitud, es decir, una superficie interior aproximada de 14,60 $\mathrm{m}^{2}$ (pensamos que entre el $50 / 65 \%$ del espacio total).

La estratigrafía del departamento estaba bastante alterada. Tras el nivel superficial encontramos un estrato de nivel de tierra de color oscuro con abundante piedra, cuya fiabilidad estratigráfica es bastante dudosa. No tenemos claro si se trata de un nivel de derrumbe, de si es 
tierra removida o si es directamente resultado del vaciado del resto de departamentos en el pasado, a modo de terrera. Aparece material, pero no todo lo completo y abundante que cabría esperar en un yacimiento como éste. Por debajo aparece un estrato de poca profundidad, justo por encima del pavimento y, por lo tanto, mucho más fiable. Presenta un llamativo color gris, tipo ceniza, lo que sumado a la existencia de abundantes carbones podría constituir un nivel de incendio. No obstante, se conserva mejor y se halla más material cerca de los muros. En la esquina suroriental se localizó una contera en posición primaría, hincada en el ángulo de la habitación, y asociada a ella restos de carbón que podrían provenir del astil. Del mismo modo, en el lado occidental se localizaron también abundantes carbones, así como algunos clavos de gran tamaño que podrían provenir de la puerta o de alguna estantería. Por último, por debajo de todo encontramos un nivel de pavimento preparado y blanquecino, excelentemente conservado (1056).

Por su parte, el Sondeo 2 se adaptó a la existencia previa de un agujero de clandestino de poca profundidad, adosado a un muro visible perfectamente en superficie antes de comenzar los trabajos (1003) (fig. 1). En el espacio delimitado se han localizado dos muros incompletos cuyo trazado es más o menos paralelo (1003 y 1008), pero la proximidad entre ambos hace complicado interpretarlos como contemporáneos. Parece que se trataría de muros de cronología anterior a la batería de departamentos situada al $\mathrm{N}$, quedando prácticamente desmantelados a la hora de reconstruir el espacio central. La estratigrafía y los materiales asociados así lo demuestran.

Al E de los muros, se documenta, por debajo del nivel superficial, un extenso estrato compacto con abundante material, restos de adobe y algunos carbones. Formando parte de él se halló una mancha de cenizas y carbones de forma circular. Del mismo modo, en el lado meridional de este sondeo, documentamos una capa compacta de tierra amarillenta, con abundantes adobes y cerámicas a mano, que podría corresponder a la fase fundacional del poblado.

En el extremo septentrional del sondeo hallamos otros dos tramos del muro longitudinal que articula todo el espacio (1012 y 1013), continuidad del muro longitudinal 1051 del Sondeo 1. Ambos tramos quedaban separados por el umbral de una puerta, acceso de un supuesto departamento. En todos los casos las estructuras se construyen sobre la roca y presentan diferentes hiladas de mampostería.
Durante los últimos días de excavación se realizó un tercer sondeo en un área diferente del yacimiento, el Sector 4. En él la montaña configura una especie de espolón o saliente hacia el S, hacia el llano de Venta Gaeta, justo en la zona de acantilados más abrupta. Decidimos excavar con celeridad por la localización superficial de dos grandes losas hincadas verticalmente, con disposición peculiar, sumado a que la tierra parecía no haber sido removida. El pequeño sondeo únicamente recuperó la alineación de losas verticales y un muro que cierra en ángulo recto con las mismas. La estratigrafía conservada era muy simple y la potencia conservada era ínfima, con la única ventaja de que el terreno parecía no haber sido alterado. Prueba de ello es el hallazgo de una fíbula anular hispánica de bronce, muy bien conservada. En superficie pudimos localizar nuevas alineaciones de piedras, por lo que la construcción parece mucho mayor y la excavación deberá ampliarse en ulteriores campañas. La espectacularidad de la ubicación, sumado a los materiales destacados, hacen de este sector un lugar interesante para continuar trabajando en el futuro, a fin de poder determinar su funcionalidad y significación.

Derivado de todos estos trabajos hemos obtenido un destacable volumen de materiales arqueológicos, principalmente cerámicos, cuyas labores de inventario, clasificación y dibujo están en marcha. En la estratigrafía hemos podido corroborar parte de la amplia diacronía que atribuíamos a este poblado a partir de su material superficial. El material más antiguo, con cerámicas a mano, importaciones fenicias y producciones torneadas toscas y de pastas grises, correspondería a los momentos iniciales de la Edad del Hierro (ss. VII-VI a. C.) documentados en los citados niveles del sondeo 2. Por último, los niveles más recientes se datarían en los ss. III-II a. C., a partir de la presencia de kalathoi e imitaciones ibéricas de piezas clásicas. En esa cronología podemos fechar la fase de abandono del Departamento 1 / Sondeo 1 , contexto que muestra una interesante variedad por tipos cerámicos, siguiendo las tipologías establecidas (Mata y Bonet 1992). Por último, en niveles superficiales de nuevo se han podido recoger cerámicas de toda la horquilla que abarca del s. VII al I a. C., tanto ibéricas (urnas de orejetas, fusayolas, decoración figurada compleja o imitaciones de formas clásicas), como importaciones (ánforas y pithoi fenicios del S peninsular, ánforas púnico-ebusitanas, ánforas itálicas vesubianas o barniz negro campaniense). 
Además de la cerámica, se ha recuperado un lote destacado de metales, un conjunto no muy abundante de fauna y se han recogido muestras de sedimento para poder llevar a cabo estudios paleobotánicos (carbones y semi1las). Por último, se han documentado diferentes materiales constructivos (adobes, restos de techumbres, hogares, etc.), así como fragmentos de molino realizados con diferentes piedras areniscas.

De forma paralela a los trabajos de excavación, se prospectaron los diferentes sectores del yacimiento. Las batidas, realizadas por parejas y con ayuda de GPS, trataban de ubicar todos los materiales visibles, a fin de identificar si existe una correlación entre diferentes zonas y cronologías concretas, dentro de la larga secuencia de ocupación del poblado. En 2017 prospectamos cuatro de estos sectores, dejando los siguientes para próximos años. Esta actividad ha sido muy interesante, ya que ha aportado una gama y diversidad de materiales mayor que la recuperada en la excavación, con piezas de todas las fases de ocupación, que van desde el final de la Prehistoria hasta el Imperio Romano.

\section{BIBLIOGRAFÍA}

DÍES, E.; GIMENO, L. (1995): El sistema defensivo de la zona SE del yacimiento ibérico del Pico de los Ajos (Yátova, Valencia), Sagvntvm-PLAV 29, 85-92.

FLETCHER, D. (1980): Los plomos ibéricos de Yátova, Serie Trabajos Varios. S.I.P. 81, València.

MATA, C.; BONET, H. (1992): La cerámica ibérica: ensayo de tipología, Estudios de arqueología ibérica y romana: homenaje a Enrique Pla Ballester, Serie Trabajos Varios. S.I.P. 89, València, 117-174.

QUIXAL, D. (2010): El Pico de los Ajos (Yátova) y el poblamiento ibérico en torno a los ríos Magro y Mijares, Revista de Estudios Comarcales Buñol-Chiva 9, 25-35.

QUIXAL, D. (2013): Las comunicaciones entre los territorios ibéricos del interior valenciano: Kelin y La Carència entre los siglos VI-I a.C., L'oppidum de la Carència de Torís i el seu territori (R. Albiach coord.), Serie Trabajos Varios. S.I.P. 116, València, 293-301. 